Special Issue of the 6th International Congress \& Exhibition (APMAS2016), Maslak, Istanbul, Turkey, June 1-3, 2016

\title{
Phase Transformation and Sintering of Algeria Clay Powder
}

\author{
L. Beddiar ${ }^{a}$, F. SAhnoune ${ }^{b, c, *}$, M. Heraiz ${ }^{b}$ And D. Redaoui ${ }^{b}$ \\ ${ }^{a}$ Department of Material Science, Faculty of Exact Science and Science of the Nature and Life, \\ University Mohamed Khaiddar Beskra, Algeria \\ ${ }^{b}$ Physics and Chemistry of Materials Lab, Department of Physics, University of M'sila, 28000, M'sila, Algeria \\ ${ }^{c}$ Research Unit on Emerging Materials (RUEM), Ferhat Abbas of Setif 01, Setif 19000, Algeria \\ Clay is one of the most used natural materials in the ceramic industry with various applications such as \\ pottery, tiles, cement and bricks. The latter are used as a building material because of their excellent thermal \\ and mechanical properties. In the present study, Algerian clay from Al-maathed area, M'sila district, was used \\ to prepare bricks. The chemical composition of the clay was determined using X-ray fluorescence. Firing of \\ clay was carried out in the temperature range $20-1000{ }^{\circ} \mathrm{C}$, at different heating rates. The present phases and \\ their transformations, the activation energy, and the sintering mechanism were evaluated using X-ray diffraction, \\ differential thermal analysis, thermogravimetric analysis and dilatometry. The activation energy for the sintering \\ mechanism obtained from non-isothermal treatments is $420 \mathrm{~kJ} / \mathrm{mol}$. The value of the Avrami exponent, $n$, is \\ determined from the shape of the crystallization exothermic dependence. It is related to $m$ parameter (a numerical \\ factor which depends on the dimensionality of crystal growth) obtained by Matusita method. Both of which are \\ about 1.2 for clay sintering. These values indicate that bulk nucleation is dominant in clay sintering by three- \\ dimensional growth, with polyhedron-like morphology controlled by interface reaction.
}

DOI: 10.12693/APhysPolA.131.566

PACS/topics: 81.05.Mh, 81.70.Pg, 81.30.Mh

\section{Introduction}

The clays from Algeria have an extensive range of applications in the refractory and ceramic manufacture. Clay is a simple and natural material, very abundant, composed of alumina silicates. The clay minerals are vastly distributed in the surface of earth. They have a characteristic small grain size and significantly influence the physical and chemical processes of soils [1-3]. Additionally, clay minerals are subjected to spontaneous modification and transformation with the change of environmental conditions, which can be illustrated by the structures and types of clay minerals. Firing in ceramic kilns was extensively reported in the literature. The relationship between the mineralogical composition of the raw materials and the phase changes during sintering was examined in the range between 900 and $100{ }^{\circ} \mathrm{C}[4,5]$. The sintering process consists in the aggregation compacting of particles.

The aim of this study is to study the thermal transformation of Algerian clay under different firing conditions in order to understand the sintering mechanism of the mineral clay. The clay raw material used in this work was obtained from the brickyard area of Al-maathed in the central area of Algeria. This Algerian clay was chosen for its wide applications in the pottery and brick making industries. The experiments of this study were conducted similar to the traditional practices of potters, to understand the sintering mechanism of these materials.

*corresponding author; e-mail: sahnounefoudil@yahoo.com
Therefore clays were manually shaped and pressed into a mould, then dried and fired. The densification behavior performance of clays fired at various temperatures under different heating rates was evaluated. It is expected that the present investigation will improve the knowledge on optimization of the clay ceramics processing.

\section{Materials and experimental procedure}

Clay materials were taken from a brick-manufacturing factory located at M'sila site in Algeria. The chemical composition of the raw clay mineral was determined by $\mathrm{X}$-ray fluorescence (XRF). Results are shown in Table I. The raw clay mineral was heated in a furnace at 200, 600,950 and $1050^{\circ} \mathrm{C}$ for 1 hour. The heating rate was $10^{\circ} \mathrm{C} / \mathrm{min}$. X-ray diffraction (XRD) was used to identify the phases formed in the heated clay powders. XRD measurements were carried out on samples using a diffractmeter system XPERT-PRO, operating at $40 \mathrm{kV}$ and $50 \mathrm{~mA}$, with scan step size of 0.0167 , using $\mathrm{CuK}_{\alpha}$ radiation of a wavelength of $1.5418 \AA$. The diffraction angle $2 \theta$ range was $6^{\circ} \leq 2 \theta \leq 90^{\circ}$. The dilatometry measurements were carried out using NETZSCH DIL 402C dilatometer. The samples were heated from room temperature to $1000^{\circ} \mathrm{C}$, at heating rates of $4,8,10,12,16$ and $20^{\circ} \mathrm{C} / \mathrm{min}$. The thermal analysis (DTA-TG) was carried out on a Setaram LABevo TG-DSC $1600^{\circ} \mathrm{C}$ equipment.

\section{Results and discussion}

Figure 1a shows a typical linear shrinkage curve $\Delta L / L_{0}$ (\%) and its first derivative as functions of temperature for the clay treated at heating rate of $20^{\circ} \mathrm{C} / \mathrm{min}$. It can be noticed that the linear shrinkage curves for the sample have three steps. The relative shrinkage of the first step, 
TABLE I

Chemical composition (wt.\%) of clay mineral (Calcined at $\left.T=700^{\circ} \mathrm{C}\right)$.

\begin{tabular}{c|c|c|c|c|c|c|c}
\hline \hline $\mathrm{Al}_{2} \mathrm{O}_{3}$ & $\mathrm{SiO}_{2}$ & $\mathrm{CaO}$ & $\mathrm{MgO}$ & $\mathrm{SO}_{3}$ & $\mathrm{~K}_{2} \mathrm{O}$ & $\mathrm{Na}_{2} \mathrm{O}$ & $\mathrm{Fe}_{2} \mathrm{O}_{3}$ \\
\hline 15.27 & 68.18 & 6.86 & 3.30 & 1.22 & 1.77 & 0.69 & 2.69
\end{tabular}

which starts at $100^{\circ} \mathrm{C}$ and ends at $250^{\circ} \mathrm{C}$, with maximum speed at $164^{\circ} \mathrm{C}$, is around $0.5 \%$. It is the result of the loss of adsorbed water. A second step (expansion) appearing at about $585^{\circ} \mathrm{C}$ results from an allotropic transformation of quartz $(\alpha \rightarrow \beta)$. This transformation is very fast and causes a sudden increase in volume, corresponding to a linear elongation of $0.25 \%$ [6]. A third relative shrinkage between $800^{\circ} \mathrm{C}$ and $940^{\circ} \mathrm{C}$, as a result, corresponds to sintering steps.
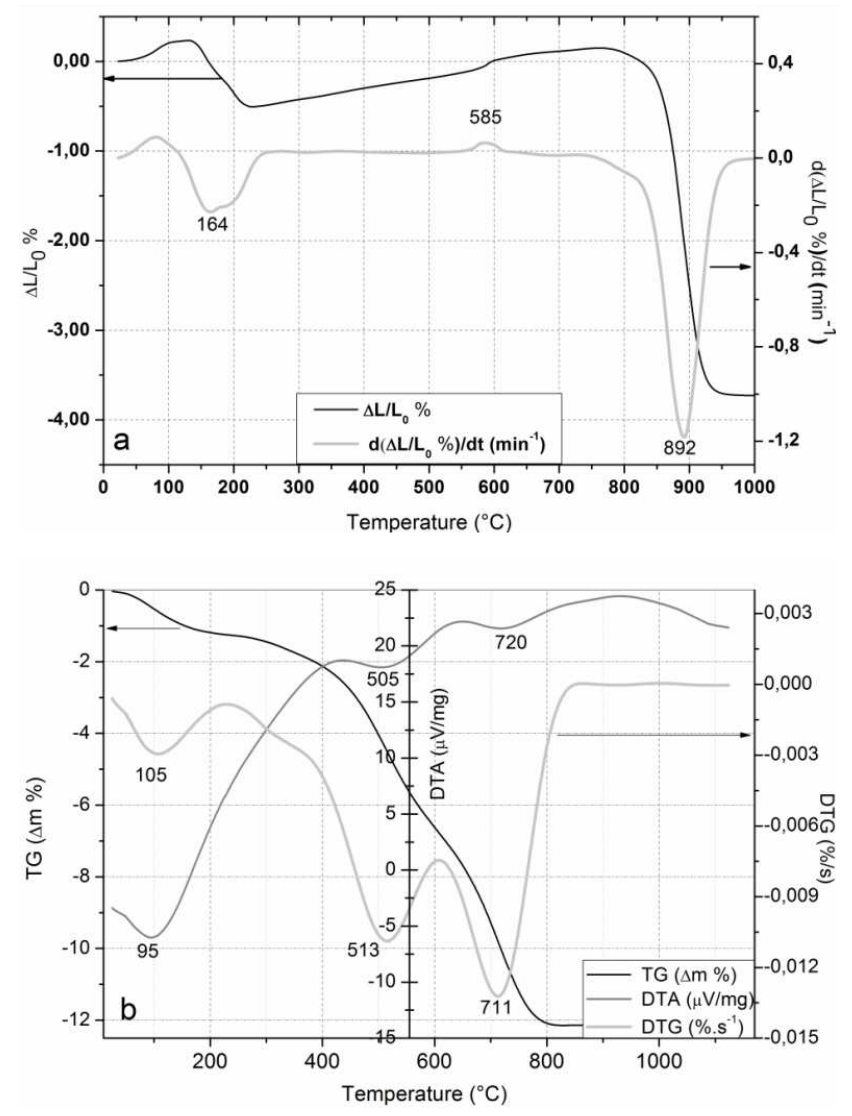

Fig. 1. (a) Shrinkage curve, (b) DTA-TG curves for clay mineral treated at heating rate of $20^{\circ} \mathrm{C} / \mathrm{min}$.

Figure 1b shows the DTA/TG curve recorded from the clay powder. It can be clearly seen that there are three endothermic peaks. The first endothermic peak at a temperature lower than $200^{\circ} \mathrm{C}$ is due to the evaporation of the adsorbed water of the raw clay mineral. The maximum rate is at $95^{\circ} \mathrm{C}$ (in DTA curves). The mass loss associated with this endothermic peak is $1.2 \%$. The second endothermic peak at $505^{\circ} \mathrm{C}$ is due to clay dehydroxylation reaction, that is overlapped with $\alpha-\beta$ quartz transformation (at about $567^{\circ} \mathrm{C}$ ). The mass loss of this transformation is about $5.3 \%$. The third endothermic peak at $720^{\circ} \mathrm{C}$ is due to the decarbonation reaction of calcite. The carbonate decomposition $(5.5 \%)$ is evident at $711^{\circ} \mathrm{C}$.

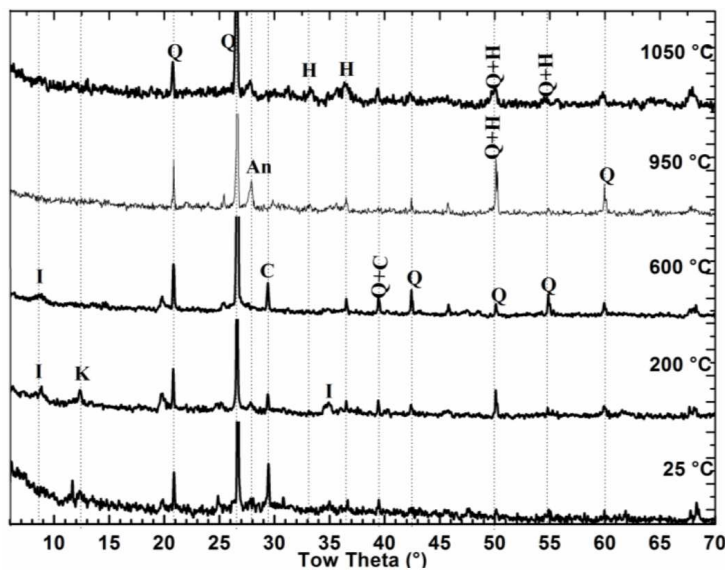

Fig. 2. Powder X-ray diffractograms of the clay mineral calcined at $200,600,950$ and $1050^{\circ} \mathrm{C}$ (Q: quartz, $\mathrm{K}$ : kaolinite, I: illite, $\mathrm{C}$ : calcite, $\mathrm{H}$ : hematite, and $\mathrm{An}$ : anorthite).

XRD spectra of clay sample hated for 1 hour between 20 and $1050{ }^{\circ} \mathrm{C}$ are presented in Fig. 2. It can be seen that between room temperature and $600^{\circ} \mathrm{C}$ the peaks of Kaolinite disappear. At $950^{\circ} \mathrm{C}$ the carbonate decomposition (calcite) is complete, and we also see the appearance of the anorthite and iron oxide (hematite). All peaks of quartz remain visible during treatment. Thus these results confirm the results obtained by dilatometry.

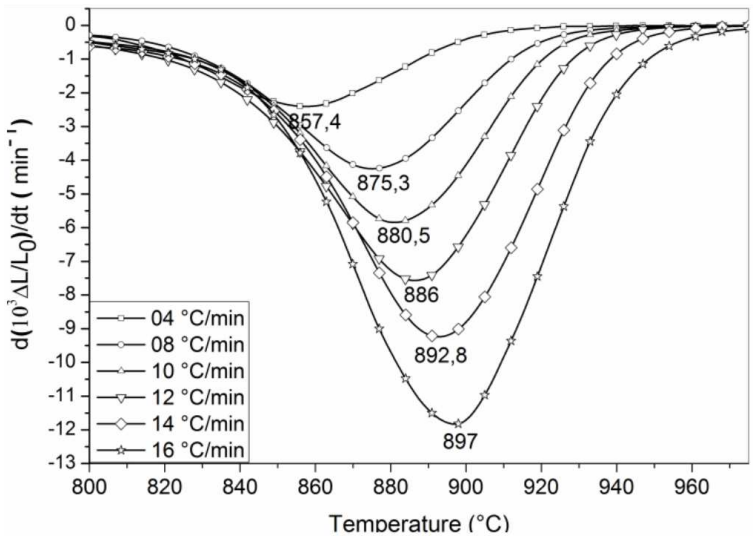

Fig. 3. First derivative of shrinkage curves for the clay mineral treated at different heating rates.

We can calculate the activation energy for the sintering of clay mineral by Kissinger-Akahira-Sunose (KAS) and Ozawa-Flynn-Wall (OFW) methods, using equations from [7-10]. Figure 3 displays the first derivative of the shrinkage curves for the sintering clay mineral at different heating rates. The temperature of the maximum of the endothermic peak, $T_{\mathrm{m}}$, shifts to a higher temperature as the heating rate increases from 4 to $20^{\circ} \mathrm{C} / \mathrm{min}$. Activation energy for the sintering of clay mineral, calculated 


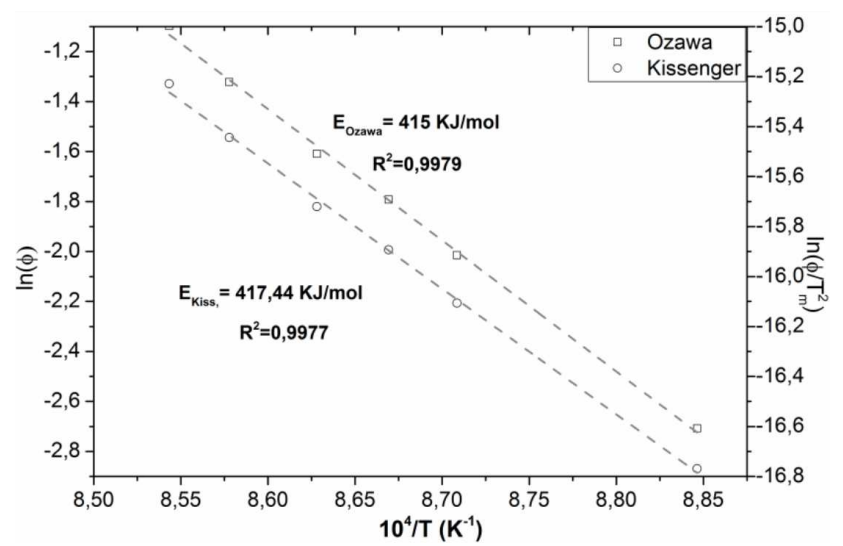

Fig. 4. Plots of $\ln (\varphi)$ and $\ln \left(\varphi / T_{\mathrm{m}}^{2}\right)$ versus $1 / T_{\mathrm{m}}$ for the sintered clay mineral.

by two methods is shown in Fig. 4. The obtained values are $E_{\text {Kiss }}=417 \mathrm{~kJ} / \mathrm{mol}$ and $E_{\text {Ozawa }}=415 \mathrm{~kJ} / \mathrm{mol}$. The value of Avrami exponent $n$ was determined from the following relation $[11,12]$

$$
n=\frac{2.5 T_{\mathrm{P}}^{2} R}{\Delta T_{\mathrm{P}} E_{\mathrm{A}}} .
$$

The average Avrami parameter of 1.19, Table II, shows that the crystallization process of the clay mineral is controlled by a diffusion growth. According to Kissinger and Matusita equations, the activation energy calculated from the slope of the Kissinger plot is $417 \mathrm{~kJ} / \mathrm{mol}$. According to Matusita equation, it is found that the parameter $m$ is 1.2 for the sintering of clay mineral. The growth morphology parameters $n$ and $m$ are both close to 1.2 , which is an indication of a three-dimensional growth of sintering clay mineral with polyhedron-like morphology. These results also indicate that the surface nucleation is the dominant mechanism in clay sintering and the crystal growth is controlled by interface reaction [12].

TABLE II

Values of the Avrami parameter, $n$.

\begin{tabular}{c|c|c|c}
\hline \hline$V[\mathrm{~K} / \mathrm{min}]$ & $T_{\mathrm{m}}[\mathrm{K}]$ & $W_{1 / 2}$ & $n$ \\
\hline 4 & 1130.4 & 56.1 & 1.13 \\
8 & 1148.3 & 55.1 & 1.19 \\
12 & 1159 & 57 & 1.17 \\
16 & 1165.8 & 56.7 & 1.21 \\
20 & 1170.5 & 57.1 & 1.20
\end{tabular}

\section{Conclusions}

The kinetics and mechanism of sintering of Algerian clay from Al-maathed was investigated using dilatometry techniques. The following conclusions are drawn from the results:

- The activation energies, measured by KissingerAkahira-Sunose and Ozawa-Flynn-Wall methods using the non-isothermal treatments were around 417 and $415 \mathrm{~kJ} / \mathrm{mol}$, respectively.

- The Avrami parameter $n$ of growth morphology was found to be around 1.2.

- The numerical factor $m$, which depends on the dimensionality of crystal growth, is found to be 1.2 , using Matusita equation.

- Bulk nucleation is dominant in clay sintering by three-dimensional growth, with polyhedron-like morphology controlled by interface reaction.

\section{References}

[1] D.E. Kherroub, M. Belbachir, S. Lamouri, Orient. J. Chem. 30, 1647 (2014).

[2] Z.Y. Zhanga, L. Huanga, F. Liu, M.K. Wang, Q.L. Fu, J. Zhu, Appl. Clay Sci. 120, 51 (2016).

[3] S. Dhanapandian, C. Manoharan, T. Ramkumar, B. Gnanavel, Acta Phys. Pol. A 118, 688 (2010).

[4] F. Pardo, S. Meseguer, M.M. Jordán, T. Sanfeliu, I. González, Appl. Clay Sci. 51, 147 (2011).

[5] M.M. Jordán, A. Boix, T. Sanfeliu, C. De la Fuente, Appl. Clay Sci. 14, 225 (1999).

[6] C. Manoharan, P. Sutharsan, S. Dhanapandian, R. Venkatachalapathy, J. Mol. Struct. 1027, 99 (2012).

[7] F. Hammami-Ben Zaied, R. Abidi, N. Slim-Shimi, A.K. Somarin, Appl. Clay Sci. 112, 1 (2015).

[8] T. Ozawa, Bull. Chem. Soc. Japan 38, 1881 (1965).

[9] J.H. Flynn, L.A. Wall, J. Res. NBS A: Phys. Chem. 70A, 487 (1966).

[10] F. Sahnoune, N. Saheb, B. Khamel, Z. Takkouk, J. Therm. Anal. Calorim. 107, 1067 (2012).

[11] C.S. Ray, W.H. Huang, D.E. Day, J. Am. Ceram. Soc. 74, 60 (1991).

[12] R.A. Ligero, J. Vazques, P. Villares, R. JimenezGaray, J. Mater. Sci. 26, 211 (1991). 